\title{
Preface: International conference: Water Resources Assessment and Seasonal Prediction
}

\author{
Wolfgang Grabs ${ }^{1}$ and Siegfried Demuth ${ }^{2}$ \\ ${ }^{1}$ Chief, International Water Affairs, German Federal Institute of Hydrology, Koblenz, Germany \\ ${ }^{2}$ Director, UNESCO International Centre for Water Resources and Global Change at German Federal Institute \\ of Hydrology, Koblenz, Germany \\ Correspondence to: Wolfgang Grabs (grabs@bafg.de)
}

Published: 17 October 2016

Changes in water quantity, and quality are occurring mainly as consequences of global and local changes including environmental factors, climate change and humaninduced changes. These changes impact the water availability which is putting stress on different sectors. Science-based knowledge to assess water resources over a range of scales both in space and time is essential to develop methodologies for water resources assessments and to improve sustainable water management practices. Linked to the dynamic assessment of water resources is the ability to provide reliable seasonal predictions of water availability and water quality. All of these need to be embedded into a framework of scientific and institutional cooperation within a larger scope of policy setting and water diplomacy.

The conference had been attended by seventy experts from twenty-eight countries who exchanged their research results and findings in the different thematic areas of the conference. A number of the presentations have been expanded into full papers and selected for this publication.

The selected papers provide an overview of research efforts and good practices focusing on changes of the hydrological cycle, predictions of freshwater availability under climate change, prediction of variations of global and regional hydrological processes and assessment of water resources linked to seasonal and inter-annual variations of hydrological components of the water cycle.
Main results of the conference have been the recognition to improve earth observing systems, improvement of methods and models to assess and predict water resources availability including improvements in seasonal predictions; recognizing that water quality is a limiting factor in water use and the necessity to enhance transboundary management of water resources in the context of water diplomacy.

The conference is a milestone in documenting current efforts to assess and predict water resources availability in the context of sustainable development.

The editors also wish to gratefully acknowledge the significant contributions made by the co-sponsoring organisations to enable the planning and conduct of the conference. Thanks go in particular to the German Federal Institute of Hydrology (BfG) who hosted the conference, World Meteorological Organization (WMO), UNESCO, the Group on Earth Observations (GEO) and IAHS. 